\title{
REFLECTION
}

\section{The Myth of the Lone Physician: Toward a Collaborative Alternative}

George W. Saba, PbD

Teresa J. Villela, MD

Ellen Chen, MD

Hali Hammer, MD

Thomas Bodenheimer, MD, MPH

University of California, San Francisco at the San Francisco General Hospital, San Francisco, California
AC Annals Journal Club selection; see inside back cover or http://www. annfammed.org/AJC/.

Conflicts of interest: authors report none.

\section{CORRESPONDING AUTHOR}

George W. Saba, PhD

Department of Family

and Community Medicine

Ward 83 , Building 80

San Francisco General Hospital

1001 Potrero Ave

San Francisco, CA 94110

Gsaba@fcm.ucsf.edu

\begin{abstract}
Cultural values and beliefs about the primary care physician bolster the myth of the lone physician: a competent professional who is esteemed by colleagues and patients for his or her willingness to sacrifice self, accept complete responsibility for care, maintain continuity and accessibility, and assume the role of lone decision maker in clinical care. Yet the reality of current primary care models is often fragmented, impersonal care for patients and isolation and burnout for many primary care physicians. An alternative to the mythological lone physician would require a paradigm shift that places the primary care physician within the context of a highly functioning health care team. This new mythology better fulfills the collaborative, interprofessional, patient-centered needs of new models of care, and might help to ensure that the work of primary care physicians remains compassionate, gratifying, and meaningful.
\end{abstract}

Ann Fam Med 2012;10:169-173. doi:10.1370/afm.1353.

\section{INTRODUCTION}

7 he traditional image of the primary care doctor is that of the lone physician, black bag in hand, braving the elements to deliver a baby, tending to a feverish child, or attending the bedside vigil of a family's dying loved one. Whether driving on a rainy, rural road in the middle of the night or treating a waiting room full of patients in a Marcus Welby-like office, this lone physician has acquired mythic proportions in American society.

Grounded in Greek mythology, the iconic lone physician embodies the noble ideals of superior knowledge, self-sacrifice, compassion, accessibility, ethical judgment, and equal treatment for all. This myth has persisted because it represents values and beliefs that have benefited both physicians and patients and is reinforced by our biomedical paradigm, social expectations of healing, health care funding, and legal culpability for malpractice.

For individuals who choose medicine as a career, the myth promises physicians a sense of control: over one's practice, over one's schedule, and over one's patient care decisions. The lone physician maintains individual responsibility and accountability, fostering pride in work that can span from making split-second, life-saving decisions to applying clinical acumen in discovering the accurate diagnosis for a complex patient. The subsequent praise and gratitude from patients and families nourish the physician, and reinforce the notion of individual heroism. This sense of control, illusory as it may be, often overshadows our awareness of the myth's dark side. In this essay, we review how this myth clashes with the current reality of primary care practice, and suggest an alternative that places the physician within the context of a highly functioning health care team. 


\section{THE REALITY OF PRIMARY CARE}

Day-to-day life for primary care physicians steers far from the idyllic image. The lone primary care physician would take an estimated 21.7 hours per day to provide all recommended acute, chronic, and preventive care for a standard panel of patients. ${ }^{1}$ In a recent survey of general internists and family physicians, $78 \%$ reported little control over their work, $27 \%$ experienced serious job dissatisfaction, and 30\% planned to leave their practice within 2 years. ${ }^{2}$ For primary care physicians who embrace the biopsychosocial model, ${ }^{3}$ the myth fundamentally fails them as they strive to be super-doc-one person to attend to the biomedical, individual, and interpersonal needs of patients and families in 15-minute increments. The "tyranny of the urgent $^{\prime \prime}$ creates a work life in which autonomy gives way to isolation, continuity to fragmentation, and compassion to burnout.

The reality of primary care work life and the perception that it is too demanding and stressful have discouraged student and resident interest in primary care careers. Only 10\% of US medical graduates in 2011 chose adult primary care residencies, and the number of family medicine residency positions filled by US medical school graduates hovers at $50 \% .^{5}$

The lone physician myth has serious consequences for patients too: $73 \%$ of US adults report difficulty accessing primary care services; $28 \%$ of Medicare patients without a primary care physician have difficulty finding one ${ }^{6}$; and a growing number of patients express dissatisfaction because "my doctor doesn't know who I am."7 The reality of primary care for most Americans falls short of the mythical doctor-patient relationship.

Current changes in health care add to the urgency of finding an alternative to this mythology. The reduction of duty hours for residents and the hegemony of the hospitalist model ensure that future generations of physicians will no longer be the lone physician caring for patients throughout their hospital stay. The patient-centered medical home and other primary care redesign models increasingly position primary care physicians in collaboration with other health professionals on a daily basis.

As we jettison many of the dysfunctional aspects of the lone physician myth, we need to craft a new narrative of a physician who thrives within a network of relationships. Doing so will require a shift in the paradigm of how we practice primary care from "I" (the lone physician) to "we" (the physician within a highly functioning health care team). A different mythology is needed to guide physicians and society about their roles and expectations within this new paradigm.

\section{CULTURAL TRANSFORMATION TO THE HIGHLY FUNCTIONING HEALTH CARE TEAM}

What does it mean to move from the lone physician to a team-based paradigm? Minimally, it means moving away from physician-centered practices to practices composed of physician-led teams. Descriptions of these care teams have included several key elements: definition of shared goals, creation of effective clinical and administrative systems, delineation of tasks, development of new team-focused training, and improvement of structures and processes of communication. ${ }^{8}$ The task for the physician is to move from thinking about my patients to our patients.

A more fundamental challenge of the new paradigm, however, is that it brings together 2 existing networks for the purpose of providing optimal clinical care-the patient network and the care team network. The patient network includes family, friends, and community supports. The care team network is the team of clinicians (physicians, nurse practitioners, and physician assistants), nurses, nonlicensed allied health workers, social workers, nutritionists, behavioral health professionals, pharmacists, and other health personnel. These 2 networks come together to form a larger system - the highly functioning health care team (HFHCT). Like any other newly formed human system, an HFHCT will need to answer fundamental questions about its functioning.

- What will be the roles and responsibilities of each team member?

- What systems and skills are needed to ensure effective communication?

- How will decisions be shared?

- How will conflict be resolved?

- How will the team foster trust and respect?

- How will the team promote the development of meaningful healing relationships?

- How will the team evolve over time?

The specific answers to these questions define the roles and tasks of each team member, and the collaborative process of working through these challenges strengthens team relationships. These answers will redefine the traditional hierarchic roles among physician, staff, and patients

In an HFHCT, each member can take the lead on different issues at different times based on their areas of expertise and interest. Rather than physicians delegating tasks, nonphysician team members can be empowered to take responsibility for entire areas of care.

Medical assistants or nurses can assume responsibility for panel management, for example, and independently order mammograms, colorectal screening studies, and diabetes-associated monitoring studies. Nurses can use guidelines to manage uncomplicated 
acute infections; because most of these infections are diagnosed though bacteriologic studies, the team can develop evidence-based standing orders. Pharmacists can independently manage uncomplicated diabetes, hypertension, and hyperlipidemia; studies have shown pharmacists can do so as well as, or better than, physicians. ${ }^{9}$ Studies have also reassured us that processes and outcomes of care can be improved by having nonphysician team members provide important components of care. ${ }^{10-13}$

In these examples, preventive, chronic, and acute care can be conducted day to day with limited physician input. True responsibility is being shared. Physicians who trust the team to share this work can comfortably focus on more-complex patients who need more of their time and subsequently feel less overwhelmed during and between patient visits.

\section{CHALLENGES FOR THE PHYSICIAN IN THE HFHCT}

How will the physician role change within the HFHCT? What cultural changes will be required for physicians to function effectively within a team?

In the lone physician model, physicians have complete control of decisions and the responsibility to carry them out. As part of an HFHCT, they must share control and decision making. Because responsibility and accountability is dispersed among team members, physicians may fear that "if I don't do it, it won't get done," or that "no one will care as much about this patient and go the extra mile." Physicians must participate in the development of mechanisms to prevent patient care fragmentation and to ensure prompt follow-up of important clinical data. Although workflow mapping and electronic health records will form part of these systems, it is essential that we implement processes that promote candid communication and strengthen a trusting working relationship among team members.

Physicians may fear losing the sense of personal pride for single-handedly achieving life-changing outcomes for patients. This pride buoys many physicians through stressful days and nights in practice: "I saved his life"; "I feel good about how I handled that problem." Will we find it as personally rewarding when a panel manager facilitates the early diagnosis of colon cancer and saves a patient's life?

Similarly, physicians may risk losing the primary relationship with their patients and families. How will it feel to have the patient in the above example bypass the physician to hug the panel manager who saved her life through routine cancer screening? Primary care physicians highly value the special relationship forged in working with a patient over time. That intense one- on-one relationship will need to be replaced with a meaningful sense of connectedness within the team.

Physicians must be cautious not to view other team members' participation as a means to unload undesirable tasks. The distribution of tasks should be guided by what is best for patient care, and team members should be included in making the decisions governing how they will function and in what roles. Anecdotes abound of medical assistants, nurses, and pharmacists who feel a renewed sense of purpose when they are given the responsibility to share in the care of a panel of patients. Yet if the change is not done well, or if they feel that the change is forced upon them, the entire endeavor may be undermined.

For patients and families, the transformation may represent the most profound change. For decades patients have viewed the lone physician as their ticket to good health. Will patients accept and value care from other team members? Anecdotes suggest that, if team members are introduced by the physician and are viewed as competent and caring, patients gladly accept them. Little research has been done, however, to elucidate whether patients will accept the new team paradigm, whether they will accept their new roles as active team members, and what it might take for them to trust the new team relationships. How can patients and families become involved in shaping how the HFHCT will function? These underexplored questions for those who are at the center of care are perhaps the most exciting and important aspect of the paradigm shift from "I" to "we."

\section{CHALLENGES IN MEDICAL EDUCATION}

Medical training fosters the idea of the lone physician, as students learn early in their education to take ownership of patients and are expected to assume complete responsibility to avoid making mistakes. ${ }^{14,15}$ In our experience training family medicine residents, this ingrained expectation poses a challenge to embracing team-based care. Residents, despite integration of team models within their training, can feel threatened that team care will dilute their sense of individual responsibility, success, control, and relationships with patients. Some residents lament that their patients bond to other team members more than to them. When team members independently act in response to a patient need, residents appropriately ask, "Who's in charge here?" Their struggle with the loss of the rewards of the lone physician is coupled with the new responsibilities of working within a team-yet another skill for residents to learn. They may experience frustration at the effort required to master this skill, feeling it easier "to just do it myself." 
A culture of self-sacrifice permeates medical training, for students, the high praise of being a team player means pitching in and staying late, not necessarily working with others to provide care. As our program has restructured inpatient clinical education to conform to new duty-hour guidelines, we have asked residents to function increasingly as collaborative inpatient team members. Even though they recognize the benefits of teamwork and of reducing their time in the hospital, residents express concerns about relinquishing ownership of their patients' care-missing the exhilaration of seeing a patient through a crisis or attending a critical family meeting. They worry that shift work subverts continuity, increases fragmentation, and creates opportunities for mistakes. They wonder whether they will lack sufficient clinical experience if they cannot care for patients throughout the course of an illness. The findings of a recent national survey of residents' perspectives on duty hours mirrors these concerns among our residents. ${ }^{16}$

\section{WHAT WILL IT TAKE TO SUPPORT CHANGE IN THE PHYSICIAN ROLE?}

For HFHCTs to develop and thrive, the administrative leadership of a clinical practice must envision this paradigm shift as essential to providing optimal care. Financial resources need to be devoted to hiring the necessary personnel and developing team processes. Team members need to be empowered to do their work through collaboratively developed guidelines and must have time to do it. Scope-of-work laws and regulations must be followed, though they will need to be reexamined so they can support rather than undermine team-based care. Professional training programs need to develop and support curricula on team-based care ${ }^{17}$ that focus on a common set of skills. Further, patients will need training to gain skills in self-advocacy and self-management. Time must be allotted for team reflection to allow members an opportunity to examine their experiences, highlight critical incidents in team care, and foster care improvement.

Broader social and cultural factors also need to change. Malpractice legislation must accommodate the reality of shared responsibility and accountability for key decision-making processes. Financial reimbursement structures must support a team approach.

In our profession's efforts to create HFHCTs, we have yet to articulate a myth that takes us from the lone physician to the team-based physician. As we strive to transform primary care, we will need to develop a new cultural image and model of the physician healer that more effectively helps us deal with the realities of practice while retaining the special relationships inherent in family medicine.

\section{THE GENESIS OF A NEW MYTHOLOGY}

One place we might look for our new model is in the field of aviation. Physicians and pilots share characteristics of the highly trained expert who makes split-second decisions to save lives. ${ }^{18}$ In the past the aviation crew and passengers assumed a passive role-parallel to how nonmedical staff and patients function within the lone physician myth. To improve safety, the aviation industry shifted its culture by introducing crew resource management, which trains flight personnel to develop communication skills, fosters cohesiveness among team members, and facilitates team decision making to prevent errors. ${ }^{19}$

This new paradigm was put to the test on January 15, 2009, when Captain C. B. "Sully" Sullenberger safely landed US Airways Flight 1549 on the Hudson River after engine failure from striking a flock of birds, and the crew helped passengers to evacuate quickly.

The flight crew had intensive training in crew resource management that prepared them to function in a crisis. Although the pilot had the responsibility and expertise in emergency landing, without the training and quick actions of the crew and the heightened sense of cooperation of the passengers, evacuation would have been delayed with loss of many lives. Referring to the landing and the rescue of Flight 1549, Sullenberger said, "We worked as a team." 20,21

Sullenberger, himself a trainer of crew resource management for US Airways, notes that to ensure safety the culture in the aviation industry needed to change their mythology from the days of pilots as "gods and cowboys" to members of a highly-functioning team. He has recommended that the health care field make a similar cultural shift training team members to work collaboratively and to communicate concerns up and down the hierarchy without fear. ${ }^{20,21}$

Health care is more complex than airplane travel, and the team members involved are more diverse than a flight crew. ${ }^{18}$ Yet aspects of the Hudson River event may help us understand how a new mythology of primary care might emerge to guide us. In this new myth, the individual hero becomes the heroic team. It can evolve only in the context of a major paradigm shift in the practice of primary care, a fundamental change in societal expectations of patients and physicians, and an innovative way to train the next generation of healers. We should not abandon the noble ideals and treasured values of the myth of the lone physician but find a way to transform them into a collaborative alternative, as we move from "I" to "we."

To read or post commentaries in response to this article, see it online at http://www.annfammed.org/content/10/2/169.

Submitted February 11, 2011; submitted, revised, July 26, 2011; accepted August 23, 2011. 
Key words: physician-patient relations; primary care; collaborative health care

Funding support: Drs Saba, Villela, Chen, and Hammer were partially supported by an HHS Health Resources Services Administration Primary Care Training Grant.

\section{References}

1. Yarnall KSH, Østbye T, Krause KM, Pollak KI, Gradison M, Michener JL. Family physicians as team leaders: "time" to share the care. Prev Chronic Dis. 2009;6(2):A59. http://www.cdc.gov/pcd/issues/2009/ apr/08_0023.htm. Accessed Dec 8, 2010.

2. Linzer M, Manwell LB, Williams ES, et al; MEMO (Minimizing Error, Maximizing Outcome) Investigators. Working conditions in primary care: physician reactions and care quality. Ann Intern Med. 2009;151(1):28-36, W6-9.

3. Engel GL. The need for a new medical model: a challenge for biomedicine. Science. 1977;196(4286):129-136.

4. Grumbach K, Bodenheimer T. A primary care home for Americans: putting the house in order. JAMA. 2002;228(7):889-893.

5. National Resident Matching Program. Results and data: 2011 main residency match. National Resident Matching Program, Washington, DC. April 2011. http://www.nrmp.org/data/resultsanddata2011 .pdf. Accessed Jun 6, 2011.

6. Bodenheimer T, Pham H. Primary care: current problems and proposed solutions. Health Aff (Millwood). 2010;29(5):799-805.

7. Safran DG. Defining the future of primary care: what can we learn from patients? Ann Intern Med. 2003;138(3):248-255.

8. Bodenheimer T. Building Teams in Primary Care, Lessons From 15 Case Studies [2-part report]. Oakland CA: California HealthCare Foundation. July 2007. http://www.chcf.org/publications/2007/07/buildingteams-in-primary-care-lessons-from-15-case-studies. Accessed Jun 6, 2011.

9. Chisholm-Burns M, Kim Lee J, Spivey CA, et al. US pharmacists' effect as team members on patient care. Med Care. 2010;48(10):923-933.
10. Baker AN, Parsons M, Donnelly SM, et al. Improving colon cancer screening rates in primary care: a pilot study emphasizing the role of the medical assistant. Qual Saf Health Care. 2009;18(5):355-359.

11. Gensichen J, von Korff M, Peitz M, et al. Case management for depression by health care assistants in small primary care practices: a cluster randomized trial. Ann Intern Med. 2009;151(6):369-378.

12. Chen EH, Thom DH, Hessler DM, et al. Using the teamlet model to improve chronic care in an academic primary care practice. J Gen Intern Med. 2010;25(Suppl 4):S610-S614.

13. Kanter M, Martinez O, Lindsay G, Andrews K, Denver C. Proactive office encounter: a systematic approach to preventive and chronic care at every patient encounter. Perm J. 2010;14(3):38-43.

14. Institute for Healthcare Improvement. http://www.ihi.org/ihi. Accessed Dec 8, 2010.

15. Oandasan IF. The way we do things around here. Can Fam Phys. 2009; 55(12):1173-1174.

16. Drolet BC, Spalluto LB, Fischer SA. Residents' perspectives on ACGME regulation of supervision and duty hours-a national survey. N Engl J Med. 2010;363(23):e34.

17. Schuetz B, Mann E, Everett W. Educating health professionals collaboratively for team-based primary care. Health Aff (Millwood). 2010;29(8):1476-1480.

18. Thomas EJ. Aviation safety methods: quickly adopted but questions remain. AHRQ Web M \& M. Jan 2006. http://www.webmm.ahrq.gov/ perspective.aspx?perspectivelD =16. Accessed Dec 8, 2010.

19. Helmreich, RL, Merritt, AC, Wilhelm JA. The evolution of crew resource management training in commercial aviation. Int'l J Aviation Psychol. 1999;9(1):19-32.

20. Clark C. Sullenberger urges hospitals to adopt aviation culture of safety. HealthLeaders Media. News. July 23, 2010. http://www .nationalnursesunited.org/news/entry/sullenberger-urges-hospitalsto-adopt-aviation-culture-of-safety/. Accessed Jun 6, 2011.

21. Sullenberger C. Highest Duty. New York, NY: William Morris; 2009. 